\title{
TEACHING A STUDY-HABIT. II
}

\author{
RALPH E. CARTER \\ University of Kansas
}

The indirect method of teaching a study-habit need not be illustrated as fully as the direct method was in Part I of this article. It is used much more than the direct method. It should not be confused with the incidental method, or lack of method, of teaching study-habits. The indirect method is distinguished from the incidental by the fact that the teacher makes definite, systematic plans for giving pupils practice enough in a method of study to lead to its habituation; it is distinguished from the direct method by the fact that the teacher does not get the pupil consciously to strive to make the method of study a study-habit.

How may a supervisor know from classroom observations alone whether teachers are efficient in getting their pupils to develop economical study-habits? How may he know whether they are using the direct or the indirect method? It will be very obvious to the classroom observer if the direct method is being used. There will be specific reference to study-habits, both in assignment and in recitation; fairly specific tests of whether pupils can use and $d o$ habitually use certain methods; and specific drills in which the attention of all the pupils is on the improvement and habituation of a clearly defined method; and the advantages of certain methods of study over others will be pointed out and sometimes demonstrated by informal experiments. One may not so easily be assured that the teacher is using the indirect method as contrasted with the incidental plan.

In order that classroom observers may decide how well studyhabits are being taught and the teachers may use the indirect method effectively, there must be a thorough understanding of the relation between the teachers' methods - in both assignment and recitation-and the study-habits which they may influence. This may be illustrated by a further discussion of teaching the habit of 
making mental cross-connections, considering it now from the standpoint of the indirect method.

In making plans to teach this habit by the indirect method, the teacher must study the possibilities of using the assignments and recitations to that end. In announcing the advance topic, she may give it a rich setting in the child's experience; she may ask study questions which will insure that pupils will be looking for similar cases and relationships. In regular recitation periods she may introduce correlated facts not easily accessible to the pupils in reference books, or she may ask class questions that will require pupils to recall related facts.

To secure better balance in training the teacher will differentiate between types of cross-connections and be sure that pupils are given examples of, and practice in making, all types. It is to be remembered, however, that the pupil is not conscious of this differentiation. The facts in today's lesson will be correlated by the teacher's statements and the answers to her questions with (I) earlier material in the same course, (2) material in other subjects,--such as history with geography, English with history, one science with another-or (3) everyday affairs (experience and other reading). These types may in turn be subdivided into $(a)$ past and $(b)$ future cross-connections.

Footnotes and citations in the context may either refer pupils to new related material or remind them of known facts that they should associate with given points under consideration. Teachers may make the best use of footnotes and citations to develop in pupils the habit of making more mental cross-connections for themselves in their reading outside of textbooks.

For a second illustration we may consider teaching the habit of varying the rate of reading, a phase of evaluation. Many pupils treat everything on a dead level-putting as much time on trivial as on important matters in their textbook reading. There is often considerable waste in time and effort when the assignment is a single reference, and usually more when several references are used.

In the latter case the teacher usually wants the pupil to supplement the notion of the topic that is gained from the first reference 
by additional points from a second and a third reference. In such cases the pupil usually reads each reference as if he were responsible for giving a faithful account of what it includes. This is usually not desirable with younger pupils. A great deal of time is thus wasted by not sketching the second and third references to get points to supplement the first reference.

If a teacher never makes the comment in a recitation that one thing is more important or less important than another, if there are no questions requiring pupils to make evaluations, and if she never indicates emphasis in making assignments or specifically indicates certain parts of the material that may be read more rapidly and certain parts that should be read more carefully, how can we expect pupils to form the habit of varying their rate of reading or to be able to judge when they may profitably do so? Many college students testify that their teachers gave them the impression that any study that was less than complete mastery of material was not academically respectable.

For a third illustration we will take teaching the habit of raising questions during study, emphasizing one phase that has not been covered in the other illustrations. The teachers who have used the indirect method most effectively in teaching this habit have studied their practices in making assignments and conducting recitations, since these may affect the pupils' habit adversely as well as favorably. They start with the question, "How can I get pupils habitually to raise more significant questions?" They know that younger children ask a great many questions when they come in contact with a new experience, and so the logical thing is to ask why school children do not ask more questions when they meet new ideas in the reading material of their courses. This question brings them to a clearer realization (I) that pupils commonly think it is a sign of weakness or lack of preparation to ask the teacher a question in class about something connected with the lesson, (2) that some of their fellow-teachers actually discourage pupils from asking questions, (3) that other teachers merely tolerate pupils' significant questions in class but do not really satisfy their desire for information, (4) that few teachers give pupils as much credit for understanding when they ask a significant question as when they 
answer a question (even when they give credit they do not always máke the pupils realize it).

The foregoing illustrations will serve to bring out at least three important advantages of the indirect method over the incidental method of teaching a study-habit. The teacher who makes systematic plans indirectly to promote the development of a studyhabit will be more likely to make a better choice and give a better balance to the features to be used in assignment and recitation. If the matter is left entirely to chance, only certain types of crossconnections will be introduced, or some of the most important forms of practice in the habit may be neglected. In the second place, it is not so much the use of the features as it is the intelligent use of them. A teacher may ask pupils very significant questions about the central thought, the purpose of a given arrangement, and the value of a certain incident in a literary selection without realizing the full possibilities of such questions. They are not merely the means of testing the pupils' understanding of the selection; they may be the means of starting pupils in the habit of raising similar questions in their later independent reading when they want to get a better understanding of a selection. When a teacher uses study questions, indicated emphasis, correlation of facts, or any other assignment or recitation feature without a full appreciation of how these features may influence some study-habit, the chances are that she will not teach the habit as well as if she did see such relationships. The third advantage was pointed out in connection with the third illustration. Systematic planning will lead to discovery of practices and conditions that are adverse to the formation of the habit and, therefore, to better-chosen methods to remedy or neutralize them.

Both the indirect and the directmethods of teaching a study-habit follow very closely our current practices in teaching other types of habits. It will give further emphasis to the point of view of this article if we differentiate the types of habits that students are expected to acquire in connection with given school subjects and then make some comparisons between methods of teaching studyhabits and other types of habits. 
One set of habits pertains to just one school subject. These habits are an integral part of the subject, and pupils must learn them in order to master the subject. They are most common in subjects that are predominantly habit-forming, such as arithmetic, writing, and beginning reading. They may be illustrated by the mastery of the various combinations in arithmetic, using the law of signs in algebra, and calling certain visual symbols by the conventional word names in reading. In these subjects certain habits are so much a part of the subject that many people do not think of them as elementary habits within a larger complex. Experimental educational psychology has revealed some such habits which had never been considered in teaching the subject. The character of eye-movements in reading is a case in point.

The study-habits such as we have under discussion constitute a second type of habit to be acquired in connection with a school subject. These may be divided into $(a)$ those limited to a certain subject and $(b)$ those more general in character. An illustration of the former is the method employed in adding a two-place column of figures-by single or double columns, by grouping, or by adding each successive number in each column. The more general type of study-habit is exemplified in the three habits mentioned in illustrating the indirect method.

Thirdly, there are habits that should be stimulated and controlled in their formation by the information given in a course. We have our most familiar illustrations of this type in such subjects as physiology and civics. One should want to bathe regularly and should have a better understanding of when and how to bathe as a result of a knowledge of certain physiological facts. In the last few years teachers have been choosing and emphasizing facts and the methods for teaching them more with reference to the teaching of certain habits than they have ever done before. Specific objectives in the form of certain habits have been set up, and there has come the realization that the best way to attain the aims that involve habits of this type is to plan more specifically and systematically for the formation of these habits. If a teacher wants pupils to form the habit of caring for their teeth, she may make 
care of the teeth a daily exercise, or she may take pains to connect the physiological facts bearing on the structure and function of teeth with the means of caring for the teeth so as to induce habits in that direction.

Teaching habits of the first type.-In teaching English composition we teach a number of simple and complex habits of the first type mentioned. We do not expect a pupil to develop all of these habits simultaneously; nor do we expect him to develop them by chance. We take up and explain relatively few things at a time. The pupils are then drilled in the use of these particular features, most of the teacher's suggestions being limited to the correction of mistakes in them. If the drill work is on sentence structure or particular grammatical forms, comparatively little criticism is made on matters pertaining to paragraph unity. Most criticism on that point must be left until habits in connection with paragraphing are taken up.

A large part of instruction consists in breaking bad habits of usage, but there is no wholesale attempt to break all bad habits simultaneously. The best teachers take pains to discover the most common faulty habits in their classes; then a few of the worst or most common are selected for special drill work. The pupils' attention is concentrated on the correct forms until these become automatic, and then attention is free to correct another group of selected faults.

In mathematics we have found that concentrated effort gives the best results. If a pupil has the habit of inaccuracy in making certain combinations or has not fully habituated the law of signs, his work will be affected materially. If these particular weaknesses can be located, a few weeks' drill on them will improve the general quality of the pupil's work in mathematics more than months of general practice. On the constructive side, we do not try to teach a great many mathematical processes (as habits) at one time. We make one or two simple processes automatic; then a more complex process is mastered; and so a hierarchy of habits is built up. But attention is concerned only with the new element each time; the other elements are on a habit basis.

Comparisons.--Instruction in English composition is concerned with training in habits of expressing thoughts; teaching pupils 
"how to study" consists in teaching them habits of getting thoughts and of fixing them in mind. The process of getting thought from the printed page is alone as complex as the process of expressing thought. We teach pupils the habits involved in the latter systematically, with emphasis on relatively few habits at a time and with more emphasis on the manner of expression (method) than on the accuracy or adequacy of facts given (content).

Who would seriously advocate changing from systematic to purely incidental training in written composition? Our courses in that field have reached a high stage of development, and the tendency is toward a more systematic form of training in oral composition. If we should teach the habits of expressing thought on the same assumption that most of us have taught habits of getting thought, we would completely do away with separate courses in composition. This article does not by any means advocate the converse-organizing a separate course in "How to Study." But it may make the contrast in present practices stand out more clearly if we consider a few of the advantages of such a course.

If we had a separate course in "How to Study," the teaching of important study-habits would not be left to chance. They would be included just as carefully as we now include all important habits of writing and speaking in our composition courses. In the second place, there would certainly be a more careful grading of study-habits for teaching purposes than we now have. There would be more thought as to what time in the course and in what connections a given habit should be taught. Thirdly, by having a more inclusive list of habits and a place in the course for teaching each, there would be more specific and consecutive drill on a habit than at present. And fourthly, there would be much more testing of pupils in study-habits, for teachers would have to test and measure improvement in study-habits if the primary aim of the course were teaching study-habits. How can any teacher confidently claim that she is teaching study-habits efficiently at the same time that she is teaching subject-matter in her course in history, science, or English, if she does not give some time to selecting carefully the study-habits she intends to teach, deciding in what order and under what circumstances to teach them, drilling pupils 
in them, and finally testing pupils in them? By planning what she would include and how she would teach such a course, any teacher will be likely to find opportunities to include more emphasis on study-habits in her regular work.

We may go to the field of mathematics for some further comparisons. Here the distinction between the first and the second types of habits is not easily made. The habit of making a mental summary of what is given and what is to be found is left to chance in arithmetic by many teachers. This habit is such an integral part of the statement of any demonstration in geometry that probably most students consider it a part of geometry rather than a method which is valuable in other connections. In fact, many students testify that this habit learned so well in geometry never became a habit of procedure with arithmetic problems. This suggests a very great advantage of the direct method over the indirect method of teaching a study-habit. By consciously habituating the method as a method, it is much more likely to be used in other connections. ${ }^{x}$

If we really want pupils to form the habit of breaking up problems-asking, "What will I have to know before I can find the required answer"-it would seem that we should call their attention to the habit and give them practice in it in much the same way that we teach them to invert the divisor and multiply in division of fractions, or to change signs when they transpose in algebra. We may want pupils to form the habit of getting and holding in mind the conditions of the problem expressed in general terms-to avoid the extra effort and confusion resulting from holding involved verbal statements and long numbers in mind. Other things being equal, the pupil who strips his problem to the essentials can plan his solution much better than the pupil who tries to hold too much in mind. Many pupils will not form this habit unless it is specifically taught.

Our conventional claims for teaching secondary mathematics include the development of certain more general mental habits.

x Those who are familiar with the most commonly accepted current theory of transfer of training will see that the direct method of teaching study-habits is consistent with it. In fact, the direct method with its conscious generalization of method is the best way to secure transfer of training in learning how to study. 
If these develop at all, they develop as study-habits first. If a mathematics teacher is going to train her pupils in the habit of developing principles and rules inductively, she must plan her work with reference to teaching the use of the inductive method in mathematics. With all the opportunity for training in habits of generalization in algebra, the average pupil gets much less than he should because many teachers use the incidental method to teach these habits, though they teach very systematically such processes as manipulation of equations and use of signs.

In both of these subjects where habits of the first type play such a large part, both recitations and examinations have been largely for the purpose of measuring the pupils' progress in these habits. So the reasons for testing pupils' progress in these habits are in general the same as the reasons for examinations. The more outstanding of these are (I) to give the teacher a chance to find out which pupils, and to what extent all of the class, are learning what they are expected to learn; (2) to give the pupil a gauge of his attainment-if it is poor, to make him see the need for improvement; if it is good, to give the satisfaction that has been shown experimentally to react favorably and result in further improvement.

Separate informal tests of particular methods of study were discussed in Part I. Then emphasis was put on the value of making the pupil realize his weakness in a particular method of study. This is one step in the direct method. Tests for the same purpose are commonly given in particular habits in composition and mathematics.

There is a further possiblity of asking direct examination questions that bear on habits. The question "What was the author's aim ?" or "What analogy will help the reader understand a certain discussion better ?" may convince the student more certainly than his answer will convince the teacher that he did not think of that when he read the passage. A question that implies that the pupil should have studied in a certain way and makes him realize that he did not do so has accomplished one of the most important purposes of questioning. It has made the pupil realize one of his weaknesses in methods of study. If the pupil has been shown the value of a 
certain method and is really trying to habituate it, it is more important for the pupil to come to a self-realization of the fact that he is not using it well than for the teacher alone to be aware of that fact.

But for the most part, quizzes and examinations will only indirectly test the pupil's use of certain study-habits. When the teacher makes out a list of questions, she will have in mind that she wants to determine how well pupils have been using certain studyhabits, as well as to test their knowledge of the subject-matter. When she has this in mind, she will be much more likely to frame questions in such a way as to find it revealed by the pupil's answers on subject-matter. No single answer will be adequate proof of the way the pupil has used the method, but the cumulative evidence from several questions carefully designed to throw light on the use of a given study-habit may be very reliable.

If teachers are using the indirect method of teaching studyhabits, they will necessarily have to put relatively greater reliance on indirect tests of pupils' use of method and lay further plans in accordance with the results obtained. Two very great advantages of the direct method of teaching should be mentioned at this point. First, the teacher may get the pupils to see that poor results in the quiz may usually be traced to poor methods of study-if sufficient time has been put upon the work. Pupils must be led to see the connection between particular mistakes on examination and the contributing causes in terms of poor study-habits. Secondly, since the pupil is trying consciously to form the habit, he will learn to determine what his study weaknesses are.

Are pupils now made as much aware of their weaknesses in methods of study (mental habits) as of their weaknesses in subjectmatter? Since improvement depends so largely on such recognition, there must be better ways of bringing it about. The pole-vaulter who fails knows that he knocked off the bar; the football player knows when he misses a tackle. They do not need to be told that they failed; they want to know why they failed, what the difference is between their technique and that of the ones who succeed. Is it enough for a pupil to know that he failed in the third problem, left out an important point in his answer on the Ashburton Treaty, or used the wrong construction in translating a word? Are we as 
teachers entirely satisfied if he can solve that problem later after seeing the correct solution, remember the point which he omitted, or give the correct construction of that word the next time? If we want those who made mistakes to profit by them and avoid similar mistakes in the future, they must be led to consider the poor study-habits that are probably responsible for them.

There is evidence that teachers are not making very great use of mistakes in subject-matter to call pupils' attention to the poor habits of study responsible for them. A question bearing on this point was asked of three sections of summer-school students-a total of 196 . Their answers to this particular question ought to be at least typical, since they were all enrolled in a course in "supervised study." They were practically all experienced teachers; about half of them were doing graduate work. The instructor in the course directed their attention to some common practices in connection with returning written quiz and examination papers to pupils. Three practices with which all were familiar were mentioned: (I) simply putting a mark on the paper, indicating its merit; (2) indicating points at which some mistake has been made; and (3) making actual corrections of the mistakes. After these ways and combinations of them had been briefly discussed the classes were asked the following question: "In addition to these three ways and the possible combinations of them, what are some of the other ways by which teachers may use returned quiz papers to make pupils realize more clearly their weaknesses?" The particular purpose of the question was to determine whether teachers think of "weaknesses" in terms of poor methods as well as of poor results. It is also an illustration of a question indirectly testing habits, since it indirectly tests the teachers' habits in marking quiz papers. Everyone gave some suggestions; some gave as many as five or six. Only 36 per cent of the 196 teachers gave a suggestion that involved trying to get the pupil to see what faulty methods were responsible for the mistakes or failure shown on the paper.

It would be interesting for us to know what percentage of our pupils think, when corrected quiz papers are about to be returned and discussed, "Now I'll find out what was wrong with my 
answers," and what percentage think "I'll find out what was wrong with my answers and why I didn't do better."

The suggestions growing out of a comparison of teaching and testing study-habits with other habits in English composition and mathematics may make some teachers feel that both the indirect and direct method will take too much of the teacher's time.

It is not within the scope of this article to elaborate the reasons for teaching study-habits. It is primarily concerned with the technique of such teaching. But if proposals are to gain acceptance, they must seem practical to the classroom teacher. We may carry our analogy one step farther to meet the possible objection of the teacher who strongly believes that the development of good mental habits and initiative in new situations is important in education, but who thinks the plans proposed here will take too much of the teacher's time. It would appall any teacher to think of teaching a boy all of the mathematics that a civil engineer has to learn if she did not remember that the course is distributed over a period of years with emphasis on only a relatively few things at one time. Think of the work involved in making a good journalist or finished platform speaker! We are willing to undertake these tasks when we have a systematic plan for them.

When we talk about the values of a high-school training, we almost invariably put more emphasis on the abilities that will be developed than on the information that will be acquired. In fact, there is a pretty clear realization that mere information will be comparatively useless unless people are trained in ways of using it. In the twelve years of school life before graduation from high school, especially when the direct method can be used advantageously in the last six years, we ought to find time to effect greater changes in mental habits and abilities.

Changing technique.-In considering the plan from as many angles as possible, we must not omit the teaching problems that are introduced when changes in study-habits are required. Most teachers recognize the fact that it is more difficult to make bad habits into good ones than to teach the correct form of habit in the beginning. In the junior and senior high schools pupils have many 
bad habits of study. The teacher's task is complicated by the problems involved in breaking these habits. Some pupils may lack entirely certain habits of reflective study-they may fail to find the author's aim, to get the plan of organization, to notice the basis of statements, to raise further questions, etc.-or they may have the habit of overlooking some condition that is most favorable to study. Some will try to use good methods but will have formed the habit of using them in an awkward way. Others will be taking unnecessary steps in study. The teacher of any subject will find these types of faulty study.

There are certain discouragements that may come to pupils when changing their technique of study. Pupils expect to meet these in types of motor-learning that involve habit-breaking much more than they do in the case of study-habits. A track athlete expects to have a temporary loss in accomplishment when he tries to change his form in vaulting or jumping. The girl who is learning to play the piano knows that she will quickly become fatigued when practicing to correct some bad habit of position. The crux of the whole matter in changing technique is keeping the attention on the process. Attention gradually dropped out when the faulty method became habitual. Now a change makes an extreme demand on attention lest the old incorrect habit assert itself. This accounts for the possible temporary falling off in accomplishment and the earlier fatigue. Yet in spite of these and other discouragements, children will work quite faithfully if they are convinced that the new way will enable them in the long run to accomplish much more than they ever could have done by the old way. They know that they will finally be using the better habits just as unconsciously and smoothly as they once used the bad habits, and with much better results.

It will be a simple but significant service to point out some simple analogies to the pupils. The more fully teachers understand the causes of pupils' discouragement in the many changes in studyhabits required, the more reasons they will see for pointing out the advantages of the method suggested. If pupils think of changes in study-habits as similar to changes in motor-habits and are fortified 
by a clear understanding of the advantages of the new way over the old way, they will be much more likely to continue their efforts until the new way is learned.

There is justification for mentioning the foregoing points, though they seem so very obvious. The writer has asked several groups of teachers and prospective teachers the direct question, "What are the most common causes of discouragement to the learner in changing technique?" The question was not asked in a detached way, but after there had been some thought and discussion on the problems involved in changing technique. The following data are given for one group of forty-eight teachers. The idea of temporary loss in accomplishment was given as a cause by thirteen ( 27 per cent); "earlier fatigue" was mentioned by seven ( 5 per cent); only five (Io per cent) used the word "attention" in stating their reasons. Many were content with vague statements about neurones and nerve paths, or with such an unanalyzed answer as "it is hard to do," or "one lapses into the old way." If we look for causes with a view to removing them, obviously we must state causes in terms that will suggest the means of doing so.

If we do not know what study-habits our pupils have, we may be requiring them to change their method of study by certain specific directions in a given lesson. If we hold them responsible for using a given method, and it is a new method, we should not require them to cover the same amount of ground in subject-matter. But we must remember this: After we teach a few study-habits well, pupils can give some attention to forming another, new study-habit and still master as long a lesson as the pupils whose study-habits are the resuit of chance. Many teachers overlook this fact when they say that the demands on them are such that they dare not neglect subject-matter to put more time on teaching pupils how to learn.

This article as a whole has considered some differentiations that may help clarify thinking in the fields of supervised and directed study. The indirect and direct methods of teaching study-habits have been illustrated. Different phases of method have been illustrated from the teaching of different study-habits. Comparisons have been made between methods of teaching and testing in the field of other habits and our practices in teaching study- 
habits. These comparisons were made for habit-breaking (changing technique) as well as for original habit formation.

We may now summarize the advantages of the direct and indirect methods of teaching a study-habit as contrasted with the incidental way which relies on chance rather than systematic training. (I) A more balanced emphasis on important study-habits is insured. (2) Difficulties in learning are broken up-relatively few things are attempted at one time-therefore the task for pupils becomes more definite and it is easier for pupils to note progress. (3) Pupils are enabled to differentiate much more clearly between more and less effective methods by having them clearly pointed out. (4) The realization of the advantages helps tide over the period of temporary discouragement in changing technique. (5) Teachers can and will test progress in the formation of study-habits more than they have in the past. (6) There is the possibility of definitely and directly connecting failure in results in subject-matter with poor methods of study. (7) Realization of their own weaknesses through direct tests of method influences pupils to want to improve and shows them where to expend effort to secure improvement. (8) Pupils have a chance to assume more responsibility for their own progress in the course. (9) There is likely to be better co-operation between pupil and teacher, since the pupil will have a better appreciation of the teacher's reasons for certain requirements. (ro) Pupils will take a greater interest in their work. (Ir) There will be a better chance for the teacher to take individual differences into consideration and give drills in specific methods of work, just as we now differentiate drill in different phases of subject-matter. (12) Pupils get the idea of differences in method and receive some training in generalizing and choosing methods. (I3) Habit will be more general if the pupil is made more conscious of the purpose and value of the habit. 